\title{
OPTIMALISASI FASILITAS GEDUNG 2 FAKULTAS TEKNIK UNTUK MENDUKUNG INTERNASIONALISASI UNS MENUJU WORLD CLASS UNIVERSITY
}

\author{
Rakai Dias Rizky \\ PROGRAM STUDI ARSITEKTUR \\ rakaidiasrizky26@gmail.com
}

\begin{abstract}
ABSTRAK
World Class University adalah suatu akreditasi yang diberikan oleh suatu lembaga internasional kepada suatu kampus yang telah mencapai suatu parameter kampus tingkat dunia. Universitas Sebelas Maret adalah salah satu perguruan tinggi di Surakarta yang sedang menuju parameter tingkat dunia. Untuk masuk kategori WCU terdapat beberapa aspek yang diperlukan. Terutama adalah aspek infrastuktur bangunan. Infrastruktur bangunan yang sesuai parameter sangat diperlukan untuk mendapatkan akreditasi WCU.
\end{abstract}

Kata Kunci: infrastruktur, sarana dan prasarana, fasilitas

\begin{abstract}
World Class University is an accreditation granted by an international institution to a campus that has achieved a parameter of a world-class campus. Sebelas Maret University is one of the tertiary institutions in Surakarta that is heading for world-class parameters. To achieve world-class parameters to be included in the WCU category, there are several aspects needed. Especially aspects of building infrastructure. Building infrastructure according to parameters is needed to get WCU accreditation.
\end{abstract}

\section{A. PENDAHULUAN}

Infrasturuktur bangunan yang ada di Universitas Sebelas Maret terus melakukan pembenahan, pembenahan dilakukan untuk mendukung Internasionalisasi UNS menuju World Class University. Menurut THE (Times Higher Education) menentukan sejumlah indikator untuk melihat suatu perguruan tinggi termasuk kelas dunia (WCU yang terdiri dari lima kategori (1) perkuliahan, terutama lingkungan belajarnya; (2) penelitian, volume, income dan reputasinya; (3) kutipan, imbas penelitian; (4) pemasukan industri, inovasi; dan (5) staf dan 
mahasiswa internasional (Agung dan Santosa, 2017, hlm. 46). Pembenahan infrastruktur bangunan akan membuat para mahasiswa lebih optimal dalam mencetak suatu prestasi di kampusnya sehingga dapat meningkatkan taraf kampus.

Selain dengan upaya pembenahan infrastruktur, penelitian ini akan mengkaji tentang pengoptimalan fasilitas sarana dan prasarana yang ada di Gedung 2 Fakultas Teknik UNS. Gedung 2 Fakultas Teknik adalah Gedung yang digunakan kegiatan pengajaran mata kuliah khusus program studi Arsitektur dan Perencanaan Wilayah dan Tata Kota. Gedung tersebut memiliki 3 lantai dengan jalan akses menuju tiap lantai terdapat 2 tangga dan terhubung jembatan dengan Gedung 5 . Kamus Besar Bahasa Indonesia, Kamus versi online/daring(dalam jaringan) mendefinisikan pengoptimalan adalah proses, cara, perbuatan mengoptimalkan (menjadikan paling baik, paling tinggi, dan sebagainya). Manfaat pengoptimalan fasilitas Gedung 2, yaitu (1) membuat para mahasiswa lebih maksimal dalam penerimaan materi pada setiap mata kuliah; (2) menambah estetika dan keindahan pada Gedung 2; dan (3) meningkatkan parameter kampus untuk memenuhi aspekaspek yang dibutuhkan agar masuk dalam kategori WCU.

Penelitian ini hendak mengkaji lebih jauh pengoptimalan fasilitas Gedung 2 Fakultas Teknik UNS untuk mendukung Internasionalisasi UNS menuju WCU. Oleh karena itu, penelitian ini penting dilakukan untuk mengetahui sejauh manakah pembenahan yang perlu dilakukan untuk memenuhi standar kampus kelas dunia.

\section{B. METODE PENELITIAN}

Penelitian ini adalah penelitian kuantitatif karena penelitian ini digunakan untuk mengetahui evaluasi pembenahan apa saja yang perlu dilakukan untuk memenuhi parameter World Class University. Menggunakan metode penelitian deskriptif. Menurut Sugiyono (Dewi, 2015, hlm. 44), penelitian deskriptif adalah "Penelitian yang dilakukan untuk mengetahui keberadaan variabel mandiri baik satu variabel atau lebih variabel yang berdiri sendiri tanpa membuat perbandingan atau mencari hubungan variabel satu sama lain”. Penelitian kuantitatif adalah suatu 
cara yang digunakan untuk menjawab masalah penelitian yang berkaitan dengan data berupa angka dan program statistik (Wahidmurni, 2017:1). Dengan menggunakan metode ini, peneliti membuat suatu gambaran yang komprehensif berdasarkan data-data yang telah dikumpulkan.

Data penelitian berupa hasil angket dari responden dan interview dengan mahasiswa arsitektur 2019 yang kemudian ditranskip menjadi bahasa tulis . Data tersebut selanjutnya akan diubah menjadi data yang bersifat kualitatif dengan analisis yang mendalam.

\section{HASIL DAN PEMBAHASAN}

Penelitian ini hendak mengkaji lebih jauh pengoptimalan fasilitas Gedung 2 Fakultas Teknik UNS untuk mendukung Internasionalisasi UNS menuju WCU. Penelitian ini dilakukan pada tanggal 1-2 Desember 2019. Dalam penelitian ini menggunakan media aplikasi google form untuk memperoleh informasi dari responden. Peneliti memakai 4 variabel penelitian, yaitu : (1) Kepuasan responden terhadap keadaan gedung 2 saat ini; (2) Respon mahasiswa terhadap sarana dan prasarana Gedung 2; (3) Jumlah responden terhadap kebersihan dan kenyamanan fasilitas di Gedung 2; dan (4) Masalah responden terhadap pentingnya pengoptimalan sarana dan prasarana untuk menuju WCU

1. Respon kepuasan mahasiswa arsitektur 2019 terhadap keadaan Gedung 2 FT UNS saat ini

Dari penelitian yang didapat, respon mahasiswa arsitektur 2019 terhadap keadaan Gedung 2 diperoleh data sebagai berikut 


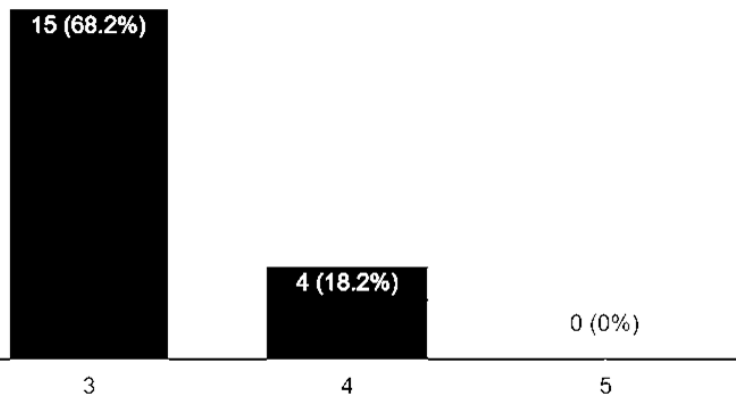

Dari 22 responden, 3 mahasiswa kurang suka terhadap keadaan Gedung 2, 4 mahasiswa menyukai keadaannya, dan 15 mahasiswa masih merasa keadaan Gedung 2 biasa aja.

2. Jumlah responden yang belum puas terhadap sarana dan prasarana di Gedung 2 saat ini

Untuk mengetahui jumlah responden yang belum puas terhadap sarana dan prasarana di Gedung 2 saat ini dipaparkan data pada diagram lingkaran sebagai berikut

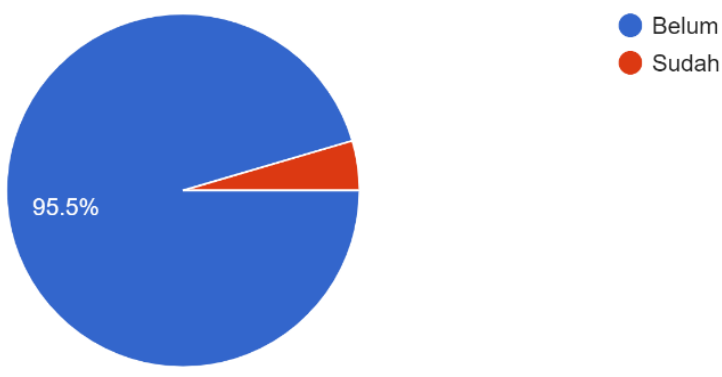

Dari 22 responden, 95,5\% merasa belum puas terhadap sarana dan prasarana yang ada di Gedung 2 saat ini. Dari data kuisioner, kebanyakan meresahkan tentang belum optimalnya sarana prasarana terutama AC dan pencahayaan ruang.

3. Tingkat presentase kepuasan responden terhadap kebersihan dan kenyamanan di Gedung 2

Untuk mengetahui tingkat kepuasan mahasiswa terhadap kebersihan dan kenyamanan Gedung 2 dipaparkan data diagram lingkaran sebagai berikut. 


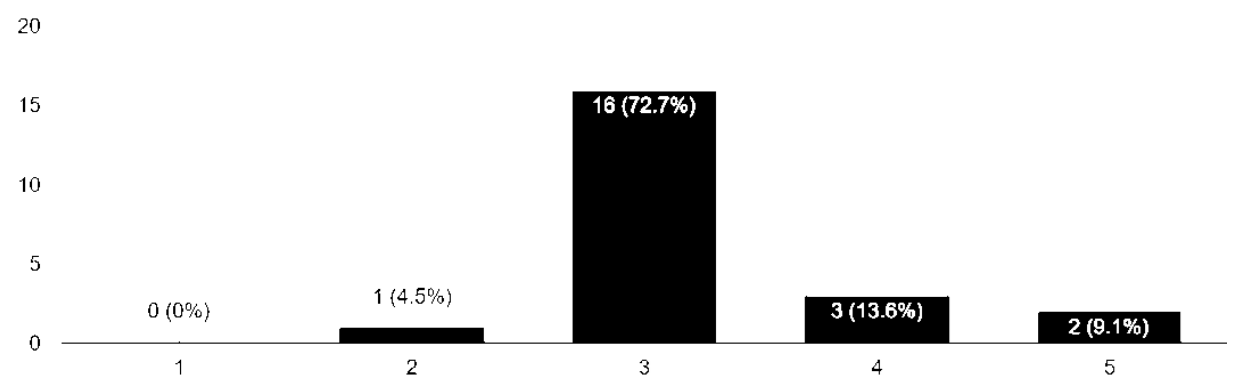

Dari 22 responden, terdapat 5 responden merasa puas terhadap kebersihan dan kenyamanan pada Gedung 2 dan terdapat 16 responden merasa masih terasa biasa aja kebersihannya.

4. Tingkat presentase pentingnya pengoptimalan sarana dan prasarana untuk menuju WCU

Untuk mengetahui pentingnya pengoptimalan sarana dan prasarana Gedung 2 untuk menuju WCU disajikan data sebagai berikut

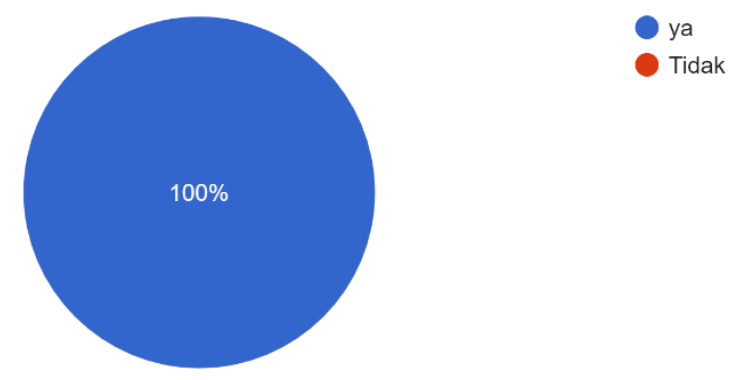

Dari 22 responden, semua merasa diperlukannya pengoptimalan sarana dan prasarana yang ada di Gedung 2 agar terpenuhinya Internasionalisasi UNS menuju WCU

\section{KESIMPULAN}

Diketahui bahwa UNS adalah salah satu kampus di Surakarta yang sedang menuju WCU. Tentu saja sudah banyak pembenahan yang telah dilakukan oleh 
kampus ini salah satunya di bidang infrastruktur bangunan. Dalam penelitian ini digunakan untuk mengetahui sejauh mana pengoptimalan sarana dan prasarana salah satu Gedung di UNS yaitu Gedung 2 Fakultas Teknik. Penelitian ini memakai 4 variable, yaitu : (1) kepuasan responden terhadap keadaan gedung 2 saat ini; (2) Respon mahasiswa terhadap sarana dan prasarana Gedung 2; (3) jumlah responden terhadap kebersihan dan kenyamanan fasilitas di Gedung 2; dan (4) masalah responden terhadap pentingnya pengoptimalan sarana dan prasarana untuk menuju WCU.

Jadi dapat disimpulkan dari penelitian ini bahwa terdapat sekitar 75\% mahasiswa arsitektur merasa Gedung 2 belum bisa bersaing dikancah Internasional sehingga diperlukan suatu pengoptimalan terhadap sarana dan prasarana yang dimiliki Gedung tersebut.

E. DAFTAR PUSTAKA

Agung, I., \& Santosa, A. (2017). Dinamika LPTK Menuju Perguruan Tinggi Kelas Dunia(World Class University/WCU).

Dewi, Ratna. (2015). Pengaruh Digital Marketing Tools Terhadap Sport Consumer Decision di Waterbom Bali. 
Kamus Besar Bahasa Indonesia (KBBI), Kamus versi online/daring (dalam jaringan). 